\title{
MARÍA DE LOS ÁNGELES LÓPEZ-ROBERTS EN PARÍS: UNA ARTISTA DE VANGUARDIA EN LA ILUSTRACIÓN ART DÉCO
}

\section{MARÍA DE LOS ÁNGELES LÓPEZ-ROBERTS IN PARIS: A VANGUARD WOMAN ARTIST IN ART DÉCO ILLUSTRATION}

\author{
Magdalena Illán Martín \\ Universidad de Sevilla. España \\ ORCID: 0000-0002-4084-9223 \\ magdaillan@us.es
}

En la década de 1930, la artista española María de los Ángeles López-Roberts (Madrid, 1902 1974) desarrolló una exitosa trayectoria como ilustradora en París. Destacada por la crítica gala por sus contribuciones a la renovación de la ilustración juvenil, en la que incorporó influencias de las vanguardias y de la estética Art Déco, este artículo analiza la intensa producción que la artista llevó a cabo como ilustradora durante el período en el que residió en la capital francesa.

Palabras clave: mujeres artistas; España; Francia; ilustración; Art Déco.

In the 1930s the Spanish woman artist María de los Ángeles López-Roberts (Madrid, 1902-1974) developed a successful career as a female illustrator in Paris. She was appreciated by French critics for her contributions to the renewal of youth illustration, in which she incorporated influences from avant-garde and Art Déco aesthetics. This paper analyzes the intense production that she carried out as a female illustrator during the period in which she lived in the French capital.

Keywords: women artists; Spain; France; illustration; Art Déco.

\section{INTRODUCCIÓN}

Por fortuna, son cada vez más numerosas las investigaciones que están aportando un mayor conocimiento sobre las artistas activas en España durante las 
primeras décadas del siglo $\mathrm{XX}^{1}$, especialmente, sobre su participación en el desarrollo de las vanguardias y, vinculada a estas, en el campo de la ilustración ${ }^{2}$. En ambos ámbitos, vanguardias e ilustración, desplegó su trayectoria María de los Ángeles López-Roberts (1902-1974), quien tuvo una reconocida presencia en el panorama artístico español de los años treinta y contribuyó notoriamente a visibilizar a las artistas en general -concurriendo a la Exposición Nacional de Bellas Artes y a iniciativas más renovadoras, como el Salón de Otoño o el Salón de los Humoristas- y, de forma concreta, a valorizar la actividad profesional de las ilustradoras a través de sus colaboraciones para diferentes revistas.

En la década de 1930, López-Roberts residió en París, donde intensificó su faceta como ilustradora y logró un relevante éxito de crítica y de público. Fue en ese periodo de su trayectoria cuando sus ilustraciones alcanzaron las más elevadas cotas de originalidad y de calidad dentro de su producción, incorporando a su estilo personal recursos plásticos y expresivos procedentes de los movimientos de vanguardia y de la estética Art Déco. Esa desconocida etapa de su creatividad es la que se examina a continuación ${ }^{3}$.

\section{MARÍA DE LOS ÁNGELES LÓPEZ-ROBERTS: EL ARTE AL SERVICIO DE LA FANTASÍA}

María de los Ángeles López-Roberts y Muguiro (Madrid, 1902-1974), también conocida en los círculos artísticos como Neneta, era hija del diplomático Mauricio López-Roberts Terry y de la aristócrata madrileña María de los Ángeles Muguiro Beruete, marquesa de Torrehermosa ${ }^{4}$. Las circunstancias familiares favorecieron, por un lado, su intensa vida social, vinculada a la nobleza española y a la carrera política y diplomática de su padre ${ }^{5}$; por otro lado, educada en un

${ }^{1}$ Las investigaciones que han posibilitado este trabajo se han desarrollado en el marco del Proyecto I+D+i Las artistas en España (1804-1939), HAR2017-84399-P, y del Grupo de investigación Laboratorio de Arte, HUM-210, Universidad de Sevilla.

2 Sobre las artistas en las vanguardias, cfr. Diego/Huici, 1999. Lomba, 2018: 143-158; 2018a: 54-64; 2019. Lomba/Morte/Vázquez, 2019. Sobre las ilustradoras, cfr. Chumillas/ MacDiego/Lleonart, 2018. González/Álix, 2019.

${ }^{3}$ Las fuentes documentales y hemerográficas consultadas para esta investigación proceden de los archivos del Institut National d'Histoire de l'Art (INHA), de la Bibliothèque Nationale de France-Arsenal (BNF-A) y de la Bibliothèque Nationale de France-François Mitterrand (BNF-FM) de París.

${ }^{4}$ Aspectos fundamentales sobre la vida de la artista han sido publicados en González/Álix, 2019: 288-293.

${ }^{5}$ En la década de 1920, la prensa publicó asiduamente noticias sobre los eventos sociales organizados por la artista, en los que destacaba su creatividad para el diseño de escenografías, ornamentos o disfraces. En el París de 1930, formó parte de la Liga Femenina Pro Paz, fue una de las fundadoras de la Union des Étrangers Catholiques en 1933 y, en 
entorno culto, cosmopolita ${ }^{6}$ e interesado por las artes -su padre fue escritor, crítico de arte y miembro de la Real Academia de Bellas Artes de San Fernando de Madrid-, recibió desde su adolescencia apoyos e incentivos para el desarrollo de su inquieta creatividad y de su actividad profesional como artista.

La formación artística de López-Roberts se llevó a cabo con Fernando Álvarez de Sotomayor y José María López Mezquita ${ }^{7}$. No obstante, sus estímulos creativos estaban alejados de postulados académicos y tradicionales, como señaló en una entrevista en 1925: "en un principio, me costó un trabajo ímprobo sujetarme a las exigencias de la técnica: jestaba tan acostumbrada a dar rienda suelta a mi fantasía...!"». De hecho, un examen de su producción inicial nos revela su interés por disciplinas artísticas muy diversificadas, vinculadas al denominado "arte decorativo", que le atraían, al igual que la ilustración, por su mayor libertad, agilidad y expresividad. Ejemplo de ello son algunas de las obras que presentó en las Exposiciones Nacionales de Bellas Artes, como el Proyecto de decoración para un cuarto de niños (56 x $36 \times 50 \mathrm{~cm})$, que obtuvo premio de Aprecio en la Sección de Arte Decorativo en 1924, la acuarela Cuatro proyectos de panneaux para una sala de música $(65 \times 50 \mathrm{~cm})$ de 1926 y el Proyecto para un panel decorativo de $1930^{\circ}$.

En relación a la producción pictórica de López-Roberts la crítica destacó su "orientación cartelista" 10 y su estética renovadora y depurada, influenciada por las vanguardias. Así, su conocido Autorretrato (Figura 1), presentado en el VI Salón de Otoño en 1925, fue elogiado por su "desenfado y sentido sintético"11. Una depuración formal que, sin embargo, no siempre fue bien acogida: "Con la preocupación de hacer simple y grande, amengua las buenas cualidades de su cuadro la señorita López Roberts"12.

1936, fue nombrada subdelegada de la Cruz Roja Española, siendo su padre el delegado de la organización.

${ }^{6}$ Con su madre viajaba habitualmente a París y el trabajo de su padre, representante del Gobierno de España en diferentes naciones, propició que la residencia familiar se trasladara a distintos países, como Suiza, donde desempeñó el cargo de ministro plenipotenciario en Berna desde 1927 a 1930, o París, desde 1930.

7 Catálogo, 1926: 35.

8 Ávila, 1925: 3.

9 Catálogo, 1924: 34 y 94. El catálogo recoge también dos óleos que la artista presentó en la sección de pintura, Canción moruna $(1,39$ x 1,35 m) y Viejo segoviano (1,30 x 0,92 m). Cfr. Catálogo, 1926: 35 y 70. El mismo catálogo menciona el óleo La sopera de plata (2,20 x 1,70 m), presentado en la sección de pintura. Cfr. también Catálogo, 1930: 65 y 38. Menciona dicho catálogo, en la sección de pintura, el óleo El té.

10 Adsuara, 1929: 75.

11 Anónimo, 1925: 3.

${ }_{12}$ Doménech, 1926: 3, se refiere el crítico a la ya mencionada pintura La sopera de plata. 
Ese carácter sintético que se advierte en su estilo le llevó a formar parte de una generación de artistas e ilustradoras que fue bien valorada por la crítica: "España cuenta con varias dibujantas notabilísimas. Algunas ya bien definidas, poseedoras de un estilo propio e inconfundible; otras... con rasgos de futura victoria... capaces de incorporarse a la vanguardia estética"13. Junto a algunas de esas artistas e ilustradoras -Marisa Roësset, Maroussia Valero, María Luisa Pérez Herrero, Gisela Ephrussi, Rosario Gil, Rosario Suárez Castiello, Amparo González Figueroa y Lola de la Vega- participó en la Exposición de pintoras organizada en el Salón del Heraldo de Madrid por Teresa de Nyssen en junio de $1929^{14}$. La exposición contribuyó, además de a visibilizar a las artistas, a promover el recurrente debate social sobre la creatividad de las mujeres: “¿Hay una sensibilidad artística femenina distinta de la masculina? ¿Tiene sexo la capacidad estética? ¿Existe, pues, en España una pintura femenina?"15. Las conclusiones de algunos críticos se adscribieron al pensamiento sexista tradicional, señalando: primero, que la creatividad de las mujeres y de los hombres era diferente ${ }^{16}$ y segundo, que las expositoras participantes debían ser especialmente valoradas por apartarse de lo supuestamente "femenino" 17 . Así, se elogió a Maroussia porque "parece un pintor" por su carácter "recio, fuerte" y "antifeminista", es decir, por no responder a la estereotipada sensibilidad femenina. López-Roberts presentó en esta muestra Camino de la escuela, obra bien valorada por una cualidad que, como se ha referido, la crítica destacaba habitualmente en su obra pictórica: su "notable depuración técnica"18; cualidad que también sería protagonista de su producción como ilustradora.

\section{LOS “ORIENTALISMOS POMPOSOS” DE LÓPEZ-ROBERTS EN EL PARÍS DE 1930}

La actividad como ilustradora de López-Roberts en el París de la década de 1930 heredó intereses que la artista había manifestado en su producción de los

${ }^{13}$ Francés, 1922: 16.

${ }_{14}$ Anónimo, 1929: 2. Una fotografía de las artistas en la inauguración de la exposición fue reproducida en la portada del Heraldo de Madrid, 4-6-1929.

15 Adsuara, 1929: 73.

16 "La sensibilidad femenina es, por lo menos, de una intensidad distinta, de una distinta penetración". Adsuara, 1929: 74.

${ }_{17}$ "Conviene advertir que ni los temas ni los estilos señalan una preferencia especial y característica, desde un punto de vista del sexo. No había, por ejemplo -jiba a decir que afortunadamente!-, ni un solo cuadro de claveles. Pero sí se notaban sensibilidades hiperestésicas-femeninas". Adsuara, 1929: 74.

${ }_{18}$ Adsuara, 1929: 75. En términos similares, Méndez Casal señaló su "sentido decorativo con tendencia a la pintura de cartel”. Méndez Casal, 1929: 16. 
años 20, especialmente las representaciones de universos fantásticos extraídos de relatos orientales, en los que podía liberar su inquieta imaginación y experimentar con estéticas exóticas, más afines a su sensibilidad creativa. Son aspectos que ya en 1922 el crítico José Francés valoró de forma entusiasta, señalando: "traza orientalismos pomposos, decorativismos plenos de gracia de riqueza cromática" 19 . Esos orientalismos pomposos habían protagonizado, en estos momentos, obras como Paseo de Babrulbadur, princesa de la China, novia de Aladino, acuarela presentada en el Salón de Otoño de 1920 e inspirada en el cuento Aladino y la lámpara maravillosa. También en la Exposición Nacional de 1924 exhibió una pintura de fantasía oriental, Canción moruna, valorada como "una franca y gozosa nota valientemente acometida y resuelta" ${ }^{20}$, que guarda similitudes con ilustraciones que la artista realizaba en estos años, como la portada de la revista Por esos mundos, en la que mostró una fantasiosa visión de la cultura árabe, en la que no faltaban las alfombras voladoras ${ }^{21}$. Y puede, en este sentido, considerarse toda una declaración de intenciones estéticas el Autorretrato que la artista remitió al Salón de Otoño de 1927, en el que posa ante un panel con enrejado romboidal de reminiscencias chinas, ataviada con una especie de floreado kimono ${ }^{22}$.

Esas motivaciones creativas se intensificaron durante el período parisino, fomentadas por el auge del Art Déco en la capital francesa, y fueron desarrolladas en su actividad como ilustradora, que se vio, como se ha señalado, consolidada y reconocida ${ }^{23}$. Así, entre 1929 y 1939 realizó en torno a 170 ilustraciones para diez libros de literatura juvenil publicados por la consagrada editorial Librairie Delagrave $^{24}$. Las ilustraciones realizadas por López-Roberts fueron, además de

19 Francés, 1922: 17.

20 Francés, 1924: 18. Canción moruna es, probablemente, la obra reproducida en $M u$ jer. Revista del Mundo y de la Moda, 16-9-1925, p. 4, protagonizada por un joven árabe que, sentado en el suelo de un interior oriental, tañe un sitar.

21 Por esos mundos, 16-5-1926, p. 1.

22 El Autorretrato $(1,15 \times 0,80 \mathrm{~m})$, remitido por la artista desde Berna, fue reproducido en Séptimo Salón de Otoño, 1927: 80.

23 Así, fue una de las cuatro mujeres que representaron a España en el Salon International du Livre d'Art de París en 1931, junto a Lola Anglada, Marga Gil Roësset y Mercedes Lario, además de Matilde Calvo Rodero en la sección de "Encuadernadores". Por otro lado, y aunque este trabajo se centra exclusivamente en la actividad como ilustradora de la artista, es reseñable que también exhibió pinturas en exposiciones colectivas e individuales parisinas, entre ellas, la conocida muestra individual Visions d'Espagne, celebrada en febrero de 1934 en la Galerie Brame. Fouquier, 1934, p. 6. Cfr. ABC, Sevilla, 29-4-1934, p. 3.

24 López-Roberts realizó ilustraciones para la Série Enfantine, dedicada a Les chefsd'oeuvre littéraires de la literatura universal, con protagonismo de autores franceses como Voltaire, George Sand, Hugo o Stendhal. La artista ilustró tanto obras contemporáneas -Le Merveilleux Coeur de cristal, Kakatoès enchanté, L'Etrange aventure de Maire-Lise, La Princesse Abeille et la princesse Amandine y Légendes au clair-de-lune- como clásicos 
admiradas por el público - prueba de ello son las múltiples reediciones que se llevaron a cabo en los años 40 y 50-, unánimemente alabadas por la crítica gala, que vio en su obra un ejemplo de la renovación del género, una revitalización de los textos clásicos y un acercamiento a las nuevas generaciones, admirando su "audacia" para la superación de los modelos rutinarios y su capacidad para "hacer honor a la imaginación del escritor" 25 .

Las ilustraciones que mayor reconocimiento reportaron a López-Roberts fueron las inspiradas en cuentos orientales, como El maravilloso corazón de cristal, La cacatúa encantada y, sobre todo, las celebradas versiones que realizó sobre Las mil y una noches: "Las Historias de las mil y una noches prestan, este año, al talento de M. A. López-Roberts, una nueva atracción: Aladin, El Caballo Mágico, $A l i-B a b a, \ldots$ son evocados en este lujoso libro"26. En dichas ilustraciones, ejecutadas entre 1929 y $1930^{27}$, la artista hace gala de su elevada capacidad como dibujadora, priorizando la expresividad y el sentido del humor y creando imágenes dinámicas y sugestivas que intensifican el carácter fantástico de los textos; asimismo, otorga a las imágenes y a los relatos un sentido novedoso y moderno, al incorporar recursos de los movimientos de vanguardia y de la ilustración Art Déco ${ }^{28}$.

Para estas publicaciones López-Roberts realizó ilustraciones en color y a página completa o en blanco y negro e integradas en el texto. En estas últimas, la artista despliega una variada gama de recursos con los que genera juegos tipográficos y arriesgadas composiciones que rompen diagonal u horizontalmente las cajas de texto (Figura 2). Las ilustraciones en color y a página completa le permiten crear composiciones complejas, en las que predominan escenografías muy estructuradas, simétricas o en zig-zag, construidas a partir de contundentes formas geométricas de perfiles afilados, que contrastan con los fantasiosos y delicados arabescos aplicados a las recurrentes nubes rizadas, a los extravagantes estampados textiles o a los exóticos fondos florales. Los puntos de vista, en picado y

adaptados -Contes des mille et une nuits e Histoire du cheval enchanté- y sin adaptar -La Belle aux cheveux d'or, Le Petit Poucet y Douze frères-. Lethève, 1967: 428.

${ }^{25}$ Fueron numerosas las críticas que elogiaron las ilustraciones de la artista. Revue des deux mondes, 11-1930, p. 943. Sabord, 1930: 3. Journal des débats politiques et littéraires, 22-12-1930, p. 4. L'Art et les artistes, 10-1932, p. 143: "Desde hace algunos años advertimos una feliz modernización de los libros juveniles... las ilustraciones son más artísticas, están bien ejecutadas... señalamos muy especialmente el bello libro Leyendas al claro de luna de Jean Rosmer, ilustrado por López-Roberts”. Cfr. Embs/Mellot, 2000: p. 265.

${ }^{26}$ Revue des deux mondes, 11-1930, p. 943.

${ }^{27}$ La artista firma y fecha cada ilustración mediante un recuadro en el ángulo inferior derecho, en el que señala sus iniciales, su primer apellido y, en números romanos, las dos últimas cifras del año de ejecución de la obra.

${ }^{28}$ Se advierten influencias de ilustradores activos en Francia en ese momento, especialmente de G. Barbier. 
contrapicado, y los constantes juegos de escalas contribuyen a dotar a las escenas de un carácter onírico e irreal, que se intensifica al introducir elementos extremadamente sintéticos y abstractos, ejecutados mediante líneas rotundas definidas por nítidos contornos.

Estas características se advierten en las ilustraciones que realizó para El maravilloso corazón de cristal (1929) ${ }^{29}$, como El paseo de Lao-Tsé en el Palais de la Lune (Figura 3), que convierte el palacio de la princesa china en un laberinto zigzagueante de planos superpuestos y angulosas arquitecturas. La artista incorpora elementos Art Déco, aunque en el cromatismo, de tonos suaves y pocos contrastados, perviven resabios de las ilustraciones que había realizado en España a mediados de los años 20. También en La cacatúa encantada (1929) ${ }^{30}$ recreó exóticos universos con inverosímiles arquitecturas inspiradas en la antigua Persia, utilizando, en esta ocasión, soluciones más arriesgadas, composiciones artificiosas de rigurosa simetría y gamas cromáticas más brillantes, estridentes y contrastadas.

Sin duda, las ilustraciones que mayor reconocimiento reportaron a LópezRoberts fueron las realizadas para Cuentos de las mil y una noches ${ }^{31}$. En ellas dispuso de una absoluta libertad creativa que le permitió, por ejemplo, situar la Historia de Aladino o la Lámpara maravillosa no en los habituales escenarios árabes, sino en la antigua China. Asimismo, la artista incorporó un cromatismo exuberante de tonalidades muy contrastadas e influencias procedentes del Cubismo y Futurismo, como se advierte en La princesa Badroulbadour (Figura 4), en la que otorga a la protagonista una imagen dinámica, inédita y vanguardista que fue ampliamente valorada por la crítica. En las otras dos historias ilustradas para este libro, Historia del Caballo encantado e Historia de Alí Babá y los Cuarenta Ladrones, utilizó recursos similares, recuperando los tradicionales escenarios árabes y sometiéndolos a un radical proceso de esquematización y geometrización que transforma, por ejemplo, al pueblo persa de Alí Babá en una irreal ciudad cubista.

Más tradicionales fueron las ilustraciones que realizó la artista para La princesa Abeille y la princesa Amandine (1929), La extraña aventura de Marie-Lise

${ }^{29}$ Para Le merveilleux coeur de cristal de Mad. Stoutz, cuento de 45 páginas publicado por L. Delagrave en 1930, llevó a cabo 12 ilustraciones, 5 de ellas en color y a página completa. BNF-A, Cote: 8-RN-31823.

${ }^{30}$ Le Kakatoès enchanté, escrito por Mme. Stoutz, fue editado por L. Delagrave en 1930; contiene 46 páginas, con 11 ilustraciones, de las cuales, 5 están ejecutadas en color y página completa. BNF-A, Cote: 8-RN-31822.

31 Contes des Mille et Une Nuits es una adaptación de Mad. H. Giraud, publicada por L. Delagrave en 1930, con 182 páginas y 56 ilustraciones, 15 en color. Se trata de una lujosa publicación, de la que se editaron 15 ejemplares numerados, en gran formato $(33$ x 25 $\mathrm{cm}$ ) y en papel Madagascar des Papeteries Lafuma. BNF-A, Cote: 4-RN-32631. Las ilustraciones de López-Roberts fueron ampliamente destacadas por, entre otros, el Mercure de France, 1930, s. p., y La Quinzaine critique des libres \& des revues, 25-5-1931, p. 310. 
(1929) o la elogiada Leyendas al claro de luna $(1931)^{32}$. Las tres publicaciones, alejadas de exotismos orientales e inspiradas en cuentos de hadas y relatos medievales, debieron estimular en menor medida su fantasía y, aunque también utiliza recursos vanguardistas en los juegos de simetrías y de escalas, no obstante, la interpretación de los escenarios recupera estéticas más convencionales. Lo mismo ocurre en las últimas ilustraciones que realizó en París, entre 1937 y 1939, para cuentos populares como La Bella con cabellos de oro de d'Aulnoy, Pulgarcito de Perrault y Los doce hermanos. El rey rana de Grimm ${ }^{33}$. Todas ellas se caracterizan por un regreso a conceptos menos arriesgados, un sentido más realista, un dibujo menos expresivo y una gama cromática de tonalidades escasamente con$\operatorname{trastadas}^{34}$.

María Ángeles López-Roberts regresó de forma permanente a España en 1940, donde continuó su trayectoria como artista y como ilustradora para revistas como $Y$ o Flechas y Pelayos. Sin embargo, a partir de ese momento, un estilo más tradicional y afín a los convencionalismos vigentes en la España franquista sustituyó el carácter original, renovador y vanguardista con el que había alcanzado, una década antes, el éxito en París.

Fecha de recepción: 25 de octubre de 2019

Fecha de aceptación: 13 de abril de 2020

${ }^{32}$ Las dos primeras obras, La princesse Abeille et la princesse Amandine (BNF-A, Cote 4-RN-31976) y L'Étrange aventure de Marie-Lise (BNF-A, Cote: 4-RN-31977) fueron escritas por Mad. Andrée de Stoutz y publicadas por Delagrave en 1930, con 45 y 41 páginas respectivamente y 12 ilustraciones, 5 de ellas en color y página completa. Legendes au clair de lune, de Jean Rosmer, pseudónimo de Jeanne Louise M. Ichard, fue publicado por Delagrave en 1932, con 240 páginas e ilustraciones en blanco y negro (BNF-A, Cote: 4-RN-34115), siendo muy bien valorado por, entre otras revistas, la Revue Belge, 1-10-1932, s. p.

33 Le petit poucet (BNF-FM, Cote: 8-Y2-83587) fue publicado en 1937, La belle aux cheveux d'or (BNF-A, Cote: 8-Y2-28159) en 1938 y Les douze frères. La grenouille (BNFA, Cote: 8-DELTA-4468) en 1939. Los tres cuentos, editados por Delagrave, contienen 31 páginas, con cinco ilustraciones en blanco y negro a página completa, frontispicio en blanco y negro y una ilustración en color en portada.

${ }^{34}$ Estas obras están más próximas a las que había realizado para publicaciones españolas antes de su marcha a París o durante la década de 1930, en la que, desde Francia, remitió ilustraciones para Blanco y Negro. Cfr. González/Álix, 2019: 290. En 1936, ilustró Cuentos de Oriente y de Occidente (vol. I) de María Victoria Maura, con ilustraciones en varias tintas para los cuatro cuentos contenidos en el libro: La leyenda del azahar, Los dos amores de Yoshiro, Zulima de Granada y El hechizo de la bruja Tiempo. 


\section{BIBLIOGRAFÍA}

Adsuara (1929): “Pintoras". En: Atlántico, 5-7-1929, pp. 73-75.

Anónimo (1925): "Algunas impresiones del interesante VI Salón de Otoño en Madrid". En: $A B C, 8-11-1925$, p. 3.

(1929): "De Bellas Artes. Exposición de pintoras". En: El Imparcial, 2-61929 , p. 2.

Ávila (1925): "Visitas de mujer. Neneta López Roberts". En: Mujer. Revista del Mundo y de la Moda, 16-9-1925, p. 3.

Catálogo Oficial de la Exposición Nacional de Bellas Artes de 1924 (1924). Madrid: Mateu Artes e Industrias Gráficas.

Catálogo Oficial de la Exposición Nacional de Bellas Artes de 1926 (1926). Madrid: Mateu Artes e Industrias Gráficas.

Catálogo Oficial de la Exposición Nacional de Bellas Artes de 1930 (1930). Madrid: Blass, S. A.

Catalogue du Salon International du Livre d'Art (1931). París: Petit Palais des Beaux-Arts.

Chumillas, Cristina/MacDiego/Lleonart, Melani (2018): Ocultas e ilustradas. Crecimiento y éxito de las ilustradoras en Valencia. Valencia: Universitat de València.

Contes des Mille et Une Nuits, adaptation de Mad. H. Giraud (1930). París: Librairie Delagrave.

D’Aulnoy, Madame (1938): La belle aux cheveux d'or. París: Librairie Delagrave.

De Diego, Estrella/Huici, Fernando (1999): Fuera de orden. Mujeres de la Vanguardia española. Madrid: Fundación Cultural Mapfre.

De Stoutz, Andrée (1930): Le merveilleux coeur de cristal. París: Librairie Delagrave.

(1930): Le Kakatoès enchanté. París: Librairie Delagrave.

(1930): L'Étrange aventure de Marie-Lise. París: Librairie Delagrave.

(1930): La princesse Abeille et la princesse Amandine. París: Librairie Delagrave.

Doménech (1926): "Exposición Nacional de Bellas Artes en los Palacios del Retiro". En: $A B C, 30-5-1926$, p. 3.

Embs, Jean-Marie/Mellot, Philippe (2000): Le siècle d'or du libre d'enfants et de jeunesse 1840-1940. París: Les Éditions de l'Amateur.

Fouquier (1934): "Les plaisirs et les jours. La semaine à Paris”. En: La Semaine à Paris, 19-1-1934, p. 6

Francés (1922): “Humoristas contemporáneos". En: Buen humor, 30-4-1922, p. 17.

(1924): "La exposición nacional. El Grabado". En: La Esfera, 12-7-1924, p. 18.

González, Marta/Álix, Josefina (2019): Dibujantas. Pioneras de la ilustración. Madrid: Museo ABC. 
Grimm (1939): Les douze frères. La grenouille. París: Librairie Delagrave.

Histoire du cheval enchanté. Contes des Mille et Une Nuits, adaptation de Mad. H. Giraud (1930). París: Librairie Delagrave.

Inventaire du fonds français après 1800, Bibliothèque National, Département des estampes, Tomo 14, Lepan-Lys.

Lethève, Jacques (1967): Inventaire du fonds français après 1800. París: LepanLys, vol. XIV.

Lomba, Concepción (2018): "En la Frontera/ Marisa Roësset (1924-1939). On the Corner". En: Archivo Español de Arte, 362, pp. 143-158.

- (2018a): "Las artistas en el Madrid moderno (1925-1939)". En AA.VV.: Madrid, musa de las artes. Madrid: Museo de Arte Contemporáneo, pp. 54-64.

(2019): Bajo el Eclipse. Pintoras en España, 1880-1939. Madrid: Consejo Superior de Investigaciones Científicas.

Lomba, Concepción/Morte, Carmen/Vázquez, M. (eds.) (2019): Las mujeres y el universo de las artes, una narración todavía incompleta. XV Coloquio de Arte Aragonés. Zaragoza: Institución Fernando el Católico (C.S.I.C.)/Fondo Económico Social Europeo.

Maura, María Victoria (1936): Cuentos de Oriente y de Occidente. San Sebastián, s. n., vol. I.

Méndez Casal (1929): sin título. En: Blanco y Negro, 16-6-1929, p. 16.

Perrault, Charles (1939): Le petit poucet. París: Librairie Delagrave.

Rosmer, Jean (1932): Legendes au clair de lune. París: Librairie Delagrave.

Sabord (1930): "La semaine littéraire". En: Paris-midi: seul journal quotidien paraissant à midi, 21-12-1930, p. 3.

Séptimo Salón de Otoño. Catálogo de pintura, escultura, grabado y arte decorativo (1927). Madrid: Asociación de Pintores y Escultores. 


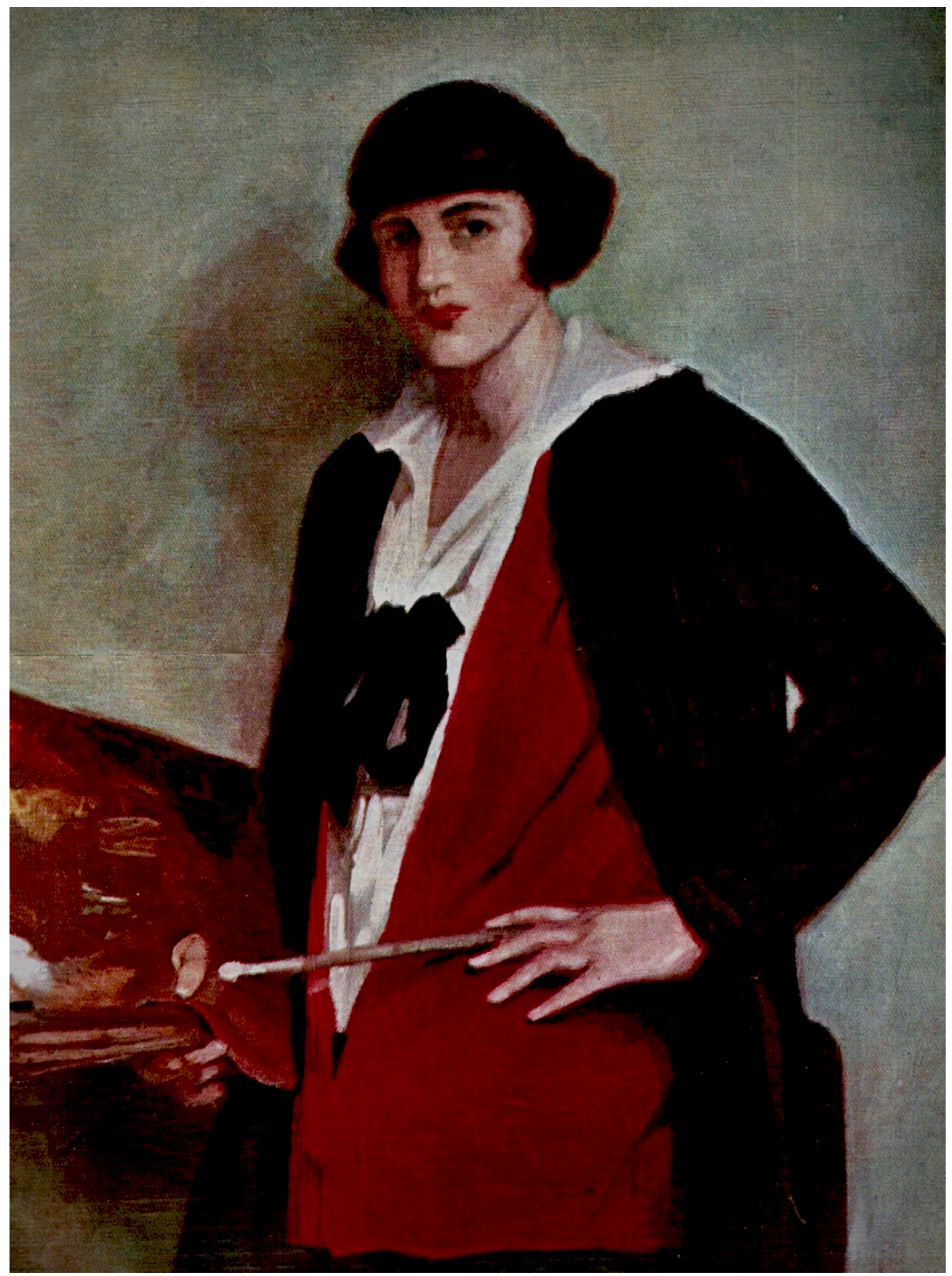

Figura 1. María de los Ángeles López-Roberts, Autorretrato, hacia 1925. 


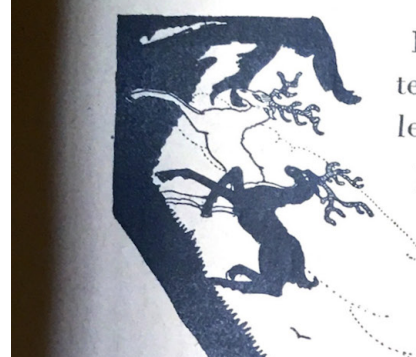

Le Prince ne pouvait faire autrement que d'accepter. Il témoigna même un certain empressement à le faire. Et la Princesse aussitôt s'occupa de faire préparer les divertissements les plus variés : réceptions, bals, concerts, festins, promenades $<$ furent organisés tout à fait princièrement. Il y eut même des chasses dans les jardins du Palais, chasses au cerf, au daim, à la biche, sans le moindre danger, pour que la Princesse pùt y assister. il point, de ce fait, l'oublier aussitòt, et, loin de tenir ses promesses, retourner au Royaume de Perse pour n’en plus jamais revenir?

Elle prit donc la parole.

"Prince, je ne puis m’opposer au désir si légitime que vous m'exprimez d'aller, au plus tòt, rassurer le Roi votre Père.

" Mais je veux néanmoins vous demander de me faire la grâce de ne me point laisser aussi vite. Puisque mon bonheur a voulu que vous fussiez amené sur la terrasse de mon Palais, au lieu d'être emporté en un lieu sauvage et inaccessible, je voudrais avoir le plaisir de vous faire connaître davantage notre pays et ses coutumes, de manière à ce que vous en emportiez des souvenirs plus précis. »

Après la chasse, le Prince et la Princesse prenaient quelque repos en un bel endroit du parc, préparé, pour les accueillir, avec des tapis, des coussins, et une collation.

\section{La Princesse} avait soin, en causant, d'a-

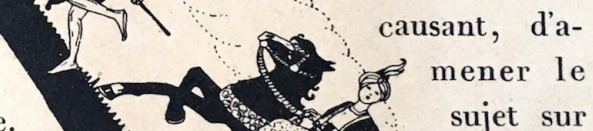
sujet sur
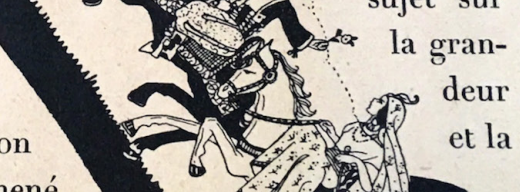

\section{é} (1) (e) (1)

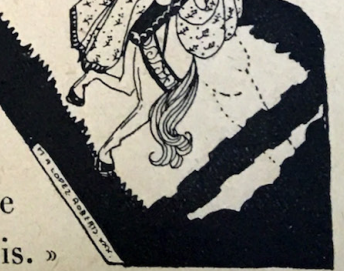

Figura 2. María de los Ángeles López-Roberts, Histoire du cheval enchanté, 1930. Librairie Delagrave, París, 1930. Bibliothèque Nationale de France-Arsenal, París. 


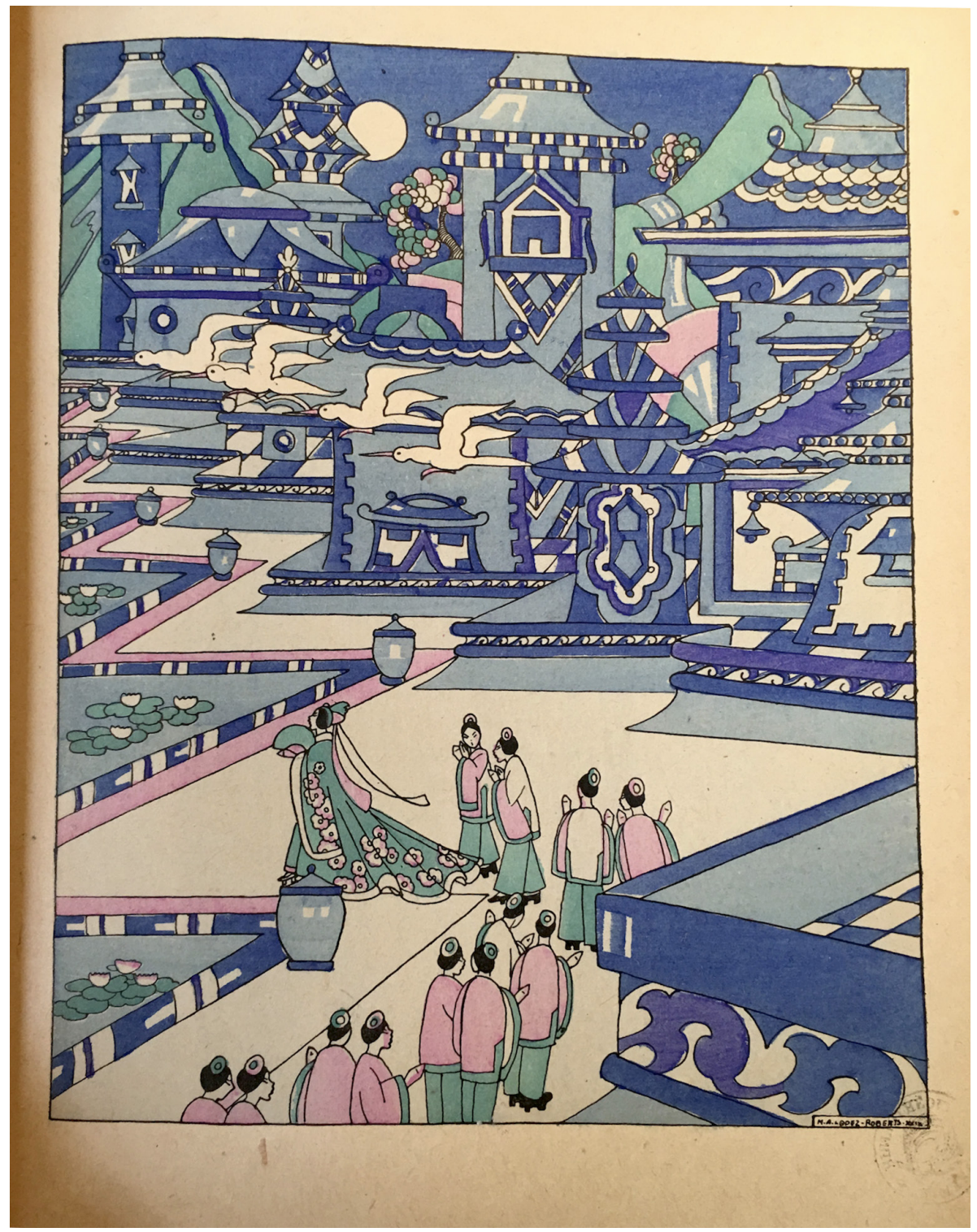

Figura 3. María de los Ángeles López-Roberts, La promenade de Lao-Tsé dans le Palais de la Lune. Le merveilleux coeur de cristal, 1929. Librairie Delagrave, París, 1930. Bibliothèque Nationale de France-Arsenal, París. 


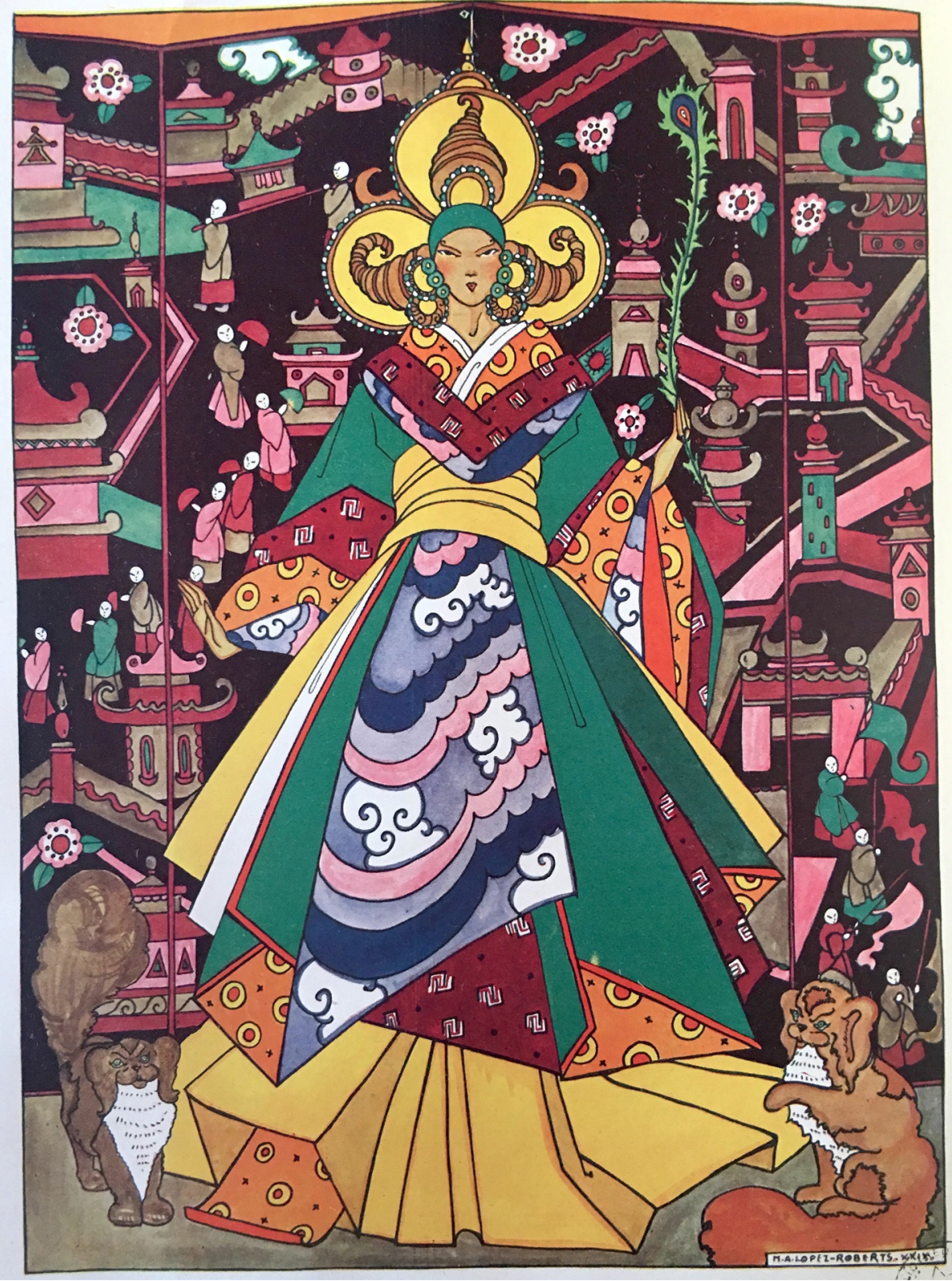

Figura 4. María de los Ángeles López-Roberts, La princesse Badroulbadour. Contes des Mille et Une Nuits, 1929. Librairie Delagrave, París, 1930. Bibliothèque Nationale de France-Arsenal, París. 